\title{
Pemetaan Mutu Pendidik dan Tenaga Kependidikan di SMP Negeri 1 Keling-Jepara-Jawa Tengah
}

\author{
Annafi Kusmaratu, Fatkuroji, Baqiyatush Sholihah \\ UIN Walisongo Semarang Indonesia \\ annafikusmaratu7@gmail.com, fatkuroji@walisongo.ac.id, \\ baqiyatush_sholihah@walisongo.ac.id
}

\begin{abstract}
Quality mapping is carried out to provide an overview of the achievement or fulfillment of the National Education Standards (SNP). This research focuses on the problems: 1) how is the quality mapping of educators and education staff based on the quality mapping instrument at SMPN 1 Keling Jepara? 2) how to improve the quality of educators and education staffs based on the standards of educators and education personnels or staffs at SMPN 1 Keling Jepara? This study uses a descriptive qualitative approach. The results showed that the quality report card as a result of quality mapping showed an increase in grades from the previous year, this was evidenced by the addition of teachers and teacher qualifications that almost reached the National Education Standards (SNP). Progress has also occurred in school principals who have met the qualifications as professional school principals, there are also administrative staff standards who must have appropriate qualified administrative personnel but there is still a lot of data that is not legible by the dapodik application which makes the standard report cards of educators and education personnels have no grade. After analyzing the quality achievement, it is continued with the principal's efforts in fostering educators and education staffs through education and training programs, MGMP and IHT.
\end{abstract}

Keywords: quality mapping, standards, educators, education personnel.

\begin{abstract}
Abstrak
Pemetaan mutu dilaksanakan untuk memberikan gambaran tentang capaian atau pemenuhan SNP. Penelitian ini mengambil fokus permasalahan: 1) bagaimana pemetaan mutu tenaga pendidik dan tenaga kependidikan berdasarkan instrumen pemetaan mutu di SMPN 1 Keling Jepara? 2) bagaimana cara meningkatkan mutu tenaga pendidik dan tenaga kependidikan berdasarkan standar pendidik dan tenaga
\end{abstract}

Annafi Kusmaratu, Fatkuroji, Baqiyatush Sholihah 
kependidikan di SMPN 1 Keling Jepara? Penelitian ini menggunakan pendekatan kualitatif deskriptif. Hasil penelitian menunjukkan bahwa rapor mutu sebagai hasil pemetaan mutu menunjukkan ada peningkatan nilai dari tahun sebelumnya, hal ini dibuktikan dengan adanya penambahan guru serta kualifikasi guru yang hampir mencapai SNP (Standar Nasional Pendidikan). Kemajuan juga terjadi pada kepala sekolah yang sudah memenuhi kualifikasi sebagai kepala sekolah profesional, ada juga standar tenaga administrasi yang harus memiliki tenaga administrasi yang berkualifikasi sesuai namun masih banyak data yang tidak terbaca oleh aplikasi dapodik yang menjadikan nilai rapor standar pendidik dan tenaga kependidikan tidak memiliki nilai. Setelah menganalisis pencapaian mutu dilanjutkan dengan upaya kepala sekolah dalam membina tenaga pendidik dan tenaga kependidikan lewat program pendidikan dan pelatihan, MGMP dan IHT.

Kata kunci: pemetaan mutu, standar, pendidik, tenaga kependidikan.

\section{PENDAHULUAN}

Pemerintah telah mengupayakan peningkatan mutu SDM (Sumber Daya Manusia) dengan mengeluarkan Permendiknas No 63 tahun 2009 tentang Sistem Penjaminan Mutu Pendidikan (SPMP) dan Peraturan Pemerintah No 19 tahun 2005 yang sudah berganti menjadi No. 32 tahun 2013 tentang Standar Nasional Pendidikan (SNP). Sistem penjaminan mutu adalah kebijakan yang dibuat pemerintah untuk meningkatkan mutu pendidikan dasar dan menengah secara sistematis, terencana dan berkelanjutan. Sistem ini bertujuan agar satuan pendidikan dapat memenuhi SNP. Untuk melaksanakan sistem penjaminan mutu, satuan pendidikan harus memiliki dua komponen sistem penjaminan mutu yang telah dikembangkan oleh Kementerian Pendidikan dan Kebudayaan, yaitu sistem penjaminan mutu internal (SPMI) dan sistem penjaminan mutu eksternal (SPME).

SPMI merupakan sistem penjaminan mutu yang dilaksanakan di satuan pendidikan dan dijalankan oleh seluruh komponen yang ada dalam satuan pendidikan, pelaksanaan ini dilakukan agar pemenuhan mutu dapat direncanakan, dilaksanakan dan dievaluasi secara internal. Sedangkan SPME merupakan sistem penjaminan mutu yang dilaksanakan oleh pemerintah, pemerintah daerah, lembaga akreditasi, dan lembaga standarisasi pendidikan. Pelaksanaan ini dimaksudkan 
agar pihak luar eksternal satuan pendidikan dapat mengetahui mutu setelah melakukan evaluasi pada satuan pendidikan. Jadi satuan pendidikan bisa dikatakan bermutu jika sudah dinyatakan bermutu oleh pihak internal maupun eksternal.

Meskipun begitu pada kenyataannya sistem penjaminan mutu ini belum berjalan di tingkat satuan pendidikan untuk semua jenjang. Dalam Peraturan Pemerintah No. 19 tahun 2005 disebutkan bahwasatuan pendidikan pada jalur formal dan non formal wajib melakukan penjaminan mutu pendidikan. Dengan adanya peraturan ini pemerintah berharap setiap jenjang pendidikan di Indonesia sadar akan pentingnya melaksanakan penjaminan mutu sebagai bentuk tanggung jawab kepada stakeholder.

Untuk sekolah yang sudah melaksanakan penjaminan mutu seperti SMPN 1 Keling Jepara, diharapkan melaksanakan tahapan yang sudah ditetapkan oleh kemendikbud. Tidak hanya mengimplementasikan sistem penjaminan mutu saja, namun juga memerlukan komitmen yang tinggi dari seluruh unsur yang terlibat dalam proses pendidikan.Tujuannya agar kualitas dalam setiap tahap seperti: input, proses dan output pada pengelolaan sekolah menjadi baik. Komitmen yang dimaksud seperti kinerja optimal yang diberikan pendidik dan tenaga kependidikan berupa jasa kepada peserta didik yang sesuai dengan kebutuhannya.

Menurut Direktorat jendral pendidikan dasar dan menengah kementerian pendidikan dan kebudayaan (2016), siklus sistem penjaminan mutu pada satuan pendidikan terdiri dari pemetaan mutu, penyusunan rencana pemenuhan, pelaksanaan pemenuhan mutu, evaluasi atau audit mutu dan penyusunan standar di atas SNP. Pada tahap awal siklus penjaminan mutu ini adalah pemetaan mutu, yang dilaksanakan secara teknis dengan mengumpulkan data dan informasi terkait 8 SNP. Pemetaan mutu secara nasional dilakukan dengan bantuan aplikasi yang dikembangkan oleh Kemendikbud.

Pemetaan mutu dilaksanakan melalui kegiatan EDS sebagai bentuk akuntabilitas terhadap pelaksanaan EDS, petugas harus menginfokan kepada sekolah untuk menyiapkan dokumen pendukung seperti kurikulum, RPP, pedoman pembelajaran dan penilaian. Hal penting yang perlu diperhatikan dalam pengisian data EDS adalah kejujuran dalam mengisi kuesioner dan akurasi data, karena data 
menjadi dasar untuk meningkatkan mutu di satuan pendidikan. Informasi yang dihasilkan serta yang akan digunakan satuan pendidikan adalah identifikasi kekuatan dan kelemahan, menyimpan rencana pengembangan sekolah kedepan, melaksanakan program pengembangan dan melaporkan kinerja pendidik dan tenaga kependidikan hal yang perlu diperbaiki. Dengan begitu satuan pendidikan mampu menunjukkan adanya perubahan perbaikan seiring dengan berjalannya waktu. Namun kenyataannya masih ada yang memasukkan data maupun pengisian yang tidak sesuai dengan kondisi sebenarnya.

Komponen satuan pendidikan yang terlibat dalam proses pemetaan mutu adalah kepala sekolah, guru (minimal 1 guru per mata pelajaran dan total minimal 8-10 guru), siswa (minimal 1 orang dan total minimal dalam sekolah 15 orang), komite, wali murid (2 perwakilan), pengawas serta pemangku kepentingan di luar satuan pendidikan. Keterlibatan pengawas sekolah dalam hal ini akan mendorong terciptanya transparansi dan keandalan data yang dikumpulkan. ${ }^{1}$

Pemetaan mutu mengacu pada SNP, berdasarkan Peraturan Pemerintah No. 32 tahun 2013 tentang Standar Nasional Pendidikan. SNP merupakan kriteria minimal tentang sistem pendidikan di seluruh wilayah hukum Negara kesatuan Republik Indonesia, yang berfungsi sebagai dasar dalam perencanaan, pelaksanaan, dan pengawasan pendidikan dalam rangka mewujudkan pendidikan Nasional yang bermutu. SNP terdiri dari standar kompetensi lulusan, standar isi, standar proses, standar pendidik dan tenaga kependidikan, standar sarana prasarana, standar pengelolaan dan standar pembiayaan. ${ }^{2}$

Implementasi 8 SNP menjadi upaya penting bagi setiap sekolah dalam menjamin kualitas pendidikannya. Upaya ini digunakan untuk menentukan aktivitas dan perbaikan program untuk mencapai tujuan pendidikan. Dari delapan standar yang diterapkan sekolah, peneliti hanya terfokus pada standar pendidik dan tenaga kependidikan dengan alasan, berdasarkan rapor mutu tahun 2019 standar pendidik dan tenaga kependidikan SMP N 1 Keling menunjukkan hasil 5,97 poin itu artinya standar belum memenuhi ketentuan. Nilai ini lebih rendah dibandingkan

1 Cepi Triatna Ridwan A. Sani, Rusjdy S. Arifin, MuhammadRif' an, Sistem Penjaminan Mutu Internal (SPMI), 1st ed. (Tangerang: Tira Smart, 2018).

${ }^{2}$ Hamid Muhammad, Petunjuk Pelaksanaan: Penjaminan Mutu Pendidikan Oleh Satuan Pendidikan (Jakarrta: Kemendikbud, 2016). 
dengan pemenuhan standar kelulusan, standar isi, standar proses, dan standar penilaian. Hal ini menarik penulis untuk meneliti lebih lanjut.

\section{HASIL PENELITIAN DAN PEMBAHASAN}

\section{A. Konsep Pemetaan Mutu}

Menurut kamus besar bahasa Indonesia, pemetaan berasal dari kata "peta" yang artinya gambaran. Menurut Duran, pemetaan merupakan upaya untuk memilah-milah, mengelompokkan dan mengklasifikasikan suatu objek menurut kriteria tertentu. Sedangkan mutu dalam konteks Total Quality Management (TQM) merupakan sebuah filosofi dan metodologi yang membantu institusi untuk merencanakan perubahan dan mengatur agenda dalam menghadapi tekanan eksternal yang berebihan. ${ }^{3}$ Menurut Duran, mutu adalah kecocokan dengan kebutuhan, bisa dikatakan mutu adalah gambaran mengenai kesesuaian, kelayakan, kemanfaatan, kebermaknaan suatu objek dengan kebutuhan perorangan atau berkelompok. Menurut J.M Juran, mutu sebagai Fitness for use artinya cocok atau layak untuk digunakan, maksudnya suatu produk atau jasa harus dapat memenuhi kebutuhan dan keinginan pelanggan. ${ }^{4}$ Menurut Hoy Jardine dan Wood, mutu merupakan kegiatan evaluasi dalam proses pendidikan demi tercapainya tujuan pendidikan dan dalam rangka mengembangkan bakat peserta didik serta memenuhi standar. ${ }^{5}$ Secara umum, mutu dapat diartikan sebagai gambaran dan karakteristik menyeluruh dari barang dan jasa yang menunjukkan kemampuannya dalam memuaskan kebutuhan yang diharapkan.

Menurut Sekretariat Direktorat Jendral Pendidikan dasar dan menengah tahun 2007, pemetaan mutu adalah proses terkait kegiatan pengumpulan, pengolahan, analisis data dan informasi tentang capaian pemenuhan SNP mulai tingkat sekolah, kabupaten/kota, provinsi hingga nasional. Berkaitan dengan pemetaan mutu, Satori (2016) menyatakan bahwa pemetaan mutu adalah serangkaian kegiatan untuk mengetahui kondisi dan situasi yang menggambarkan peta mutu pendidikan SNP

\footnotetext{
${ }^{3}$ Edward Sallis, Total Quality Management in Education, ed. Ahmad Ali Riyadi dan Fahrurrozi (Yogyakarta: IRCisoD, 2012).

${ }^{4}$ Darwin Kadarisma Muhandri, Tjahja, Sistem Jaminan Mutu Industri Pangan (Bogor: IPB Press, 2012).

${ }^{5}$ Ari Prayoga, "Manajemen Penjaminan Mutu Madrasah" (UIN Sunan Gunung Djati Bandung, n.d.).
} 
yang dilakukan oleh satuan pendidikan, penyelenggara, pemerintah daerah dan pemerintah dalam kurun waktu tertentu.

Mutu pendidikan Indonesia dinilai berdasarkan capaian kinerja satuan pendidikan atas SNP. Untuk itu pemetaan mutu pendidikan akan memberikan gambaran kepada berbagai pemangku kepentingan tentang capaian pemenuhan SNP. ${ }^{6}$ Berdasarkan Permendikbud No. 28 tahun 2016 tentang sistem penjaminan mutu pendidikan pada pasal 5 ayat (1) menyatakan bahwa pemetaan mutu adalah siklus pertama dalam SPMI. ${ }^{7}$

Menurut Akdon pemetaan mutu adalah bentuk evaluasi kinerja organisasi berupa serangkaian kegiatan untuk mengetahui kondisi dan situasi yang menggambarkan peta capaian mutu terkait SNP. Fungsi evaluasi kinerja adalah untuk mengetahui tingkat keberhasilan dan kegagalan suatu organisasi dan memberikan masukan untuk mengatasi permasalahan yang ada.

Dari penjabaran di atas dapat disimpulkan bahwa, pemetaan mutu adalah serangkaian kegiatan untuk mengetahui kondisi dan situasi pendidikan dengan cara mengumpulkan data, mengolah dan menganalisis data agar terpenuhinya SNP.

Dalam buku panduan pelaksanaan pemetaan mutu pendidikan sasaran program Pemetaan Mutu Pendidikan melibatkan:

a. Seluruh satuan pendidikan baik Negeri maupun Swasta dari jenjang TK, SD, SMP, SLB, SMA dan SMK.

b. Seluruh PTK yang aktif bertugas pada satuan pendidikan, seperti:

1) Kepala sekolah

2) perwakilan guru (minimal 1 guru/mata pelajaran, total minimal 810 guru)

3) siswa (minimal 5 siswa/ tingkat kelas, total minimal dalam satuan pendidikan 15)

4) komite sekolah (minimal 1 orang dan 2 perwakilan wali murid)

5) pengawas pembina.

Pelaksanaan program pemetaan mutu pendidikan, sebagai berikut:

\footnotetext{
${ }^{6}$ Wayan Murnasa Surnaya, Ketut, Peta Mutu Pendidikan Jenjang SD Kabupaten Bangli (Bali: LPMP Bali, 2018).

7 Peraturan menteri pendidikan dan kebudayaan No. 28 tahun 2016, "Sistem Penjaminan Mutu Pendidikan Dasar Dan Menengah" (2016).
} 
Memetakan mutu pendidikan berdasarkan SNP melalui kegiatan Evaluasi Diri Sekolah (EDS) yang nantinya akan menghasilkan peta mutu (capaian standar), mengetahui masalah serta mendapatkan rekomendasi perbaikan.

Mekanisme pelaksanaan program pemetaan mutu pendidikan berdayakan teknologi informasi dan komunikasi (online). ${ }^{8}$ Adapun tahapannya sebagai berikut :

1) Responden (kepala sekolah, guru, siswa dan komite) mengisi instrument lewat aplikasi PMP, setelah seluruhnya lengkap maka akan dihasilkan rapor mutu.

2) Berdasarkan hasil rapor mutu yang sudah jadi, selanjutnya kepala sekolah melakukan validasi dan verifikasi.

3) Apabila kepala sekolah tidak menerima hasil rapor mutu standar, kepala sekolah dapat meminta responden mengisi ulang.

4) Setelah semua lengkap dan sesuai dengan kondisi sekolah, kepala sekolah mengirim data PMP ke server setelah mengisi pakta integritas.

5) Pengawas sekolah dapat melakukan verval rapor mutu PMP sekolah binaannya kapan saja dan dimana saja karna secara online dan setelah lengkap dapat mengirim ke server setelah mengisi pakta integritas.

6) Setelah semua lengkap maka rapor mutu sekolah dapat dipublikasikan dan digunakan untuk PMP.9

\section{Instrumen pemetaan standar pendidik dan tenaga kependidikan}

Menurut Suharsimi Arikunto instrumen merupakan alat bantu untuk mengumpulkan data agar kegiatan tersebut menjadi sistematis. Instrumen pemetaan mutu mengacu pada delapan SNP, bisa juga menggunakan instrumen yang dikembangkan oleh pemerintah maupun badan akreditasi. Pelaksanaan pemetaan mutu ini dilakukan dibawah supervisi kepala sekolah dan pengawas.

8 Abi Sujak, Panduan Pelaksanaan Pemetaan Mutu Pendidikan (Jakarta: Kementerian Penddik dan Kebudayaan Badan Pengembangan Sumber Daya Manusia Pendidikan dan Kebudayaan dan Penjaminan Mutu Pendidikan, 2013).

${ }^{9}$ LPMP, Mekanisme Pemetaan Mutu Tahun 2019 (Banten: Direktorat jendral pendidikan dasar dan menengah kementerian pendidikan dan kebudayaan, 2019). 
Pelaksanaan pemetaan mutu menggunakan instrumen yang dikembangkan oleh pemerintah dan diisi oleh komponen satuan pendidikan. Ssetelah semua terisi, instrumen akan diserahkan ke pengawas bersama data pendukung. Setelah itu pengawas sekolah akan melakukan verifikasi dan validasi data sehingga dapat diperoleh data yang benar-benar valid. Hal ini menunjukkan bahwa instrumen pemetaan mutu dilakukan melalui Evaluasi Diri Sekolah (EDS). ${ }^{10}$ Evaluasi diri merupakan salah satu aspek penting dalam penjaminan mutu dan juga perlu dilakukan dalam penilaian akreditasi satuan pendidikan. EDS menggunakan analisis SWOT dalam perencanaan pengembangan sekolah dengan maksud untuk mengetahui kekuatan dan kelemahan sekolah dari beberapa aspek SNP. ${ }^{11}$

\section{B. Pemetaan Mutu Pendidikdan Tenaga Kependidikan di SMPN 1 Keling Jepara}

Berdasarkan UU No. 20 tahun 2003 tentang Sistem pendidikan nasional, pendidikan nasional berfungsi untuk mengembangkan kemampuan dan membentuk watak serta peradaban bangsa. Kppembentukan karakter bangsa melalui pendidikan diwujudkan dalam suasana belajar dan proses pembelajaran, hal ini bertujuan agar peserta didik dapat secara aktif mengembangkan potensi dirinya untuk memiliki kekuatan spiritual keagamaan, pengendalian diri, kepribadian, kecerdasan, akhlak mulia serta keterampilan yang diperlukan dirinya, masyarakat maupun bangsa. Di samping itu akan terbentuk SDM yang terampil, profesional, dan berkualitas sebagai pelaksana pembangunan dalam mewujudkan tujuan nasional. Untuk itu pemenuhan standar pendidik dan tenaga kependidikan menjadi sangat penting bagi peningkatan mutu sekolah karena pendidik dan tenaga kependidikan berperan aktif dalam penyelenggaraan proses pembelajaran siswa.

Kualitas sekolah akan tercapai apabila komponen yang terdapat di satuan pendidikan telah memenuhi syarat. Sebagaimana ditegaskan dalam PP No. 19 tahun 2005 pasal 28 bahwa pendidik dan tenaga kependidikan harus memiliki kualifikasi akademik dan kompetensi,

\section{Pendidikan.}

${ }^{10}$ Muhammad, Petunjuk Pelaksanaan: Penjaminan Mutu Pendidikan Oleh Satuan

${ }^{11}$ Ridwan A. Sani, Rusjdy S. Arifin, MuhammadRif' an, Sistem Penjaminan Mutu Internal (SPMI). 
sehat jasmani dan rohani serta memiliki kemampuan untuk mewujudkan tujuan pendidikan nasional. Kualifikasi akademik yang dimaksudkan adalah tingkat pendidikan minimal yang harus dipenuhi oleh pendidik dan tenaga kependidikan yang dibuktikan dengan ijazah atau sertifikat keahlian yang relevan sesuai dengan ketentuan perundang-undangan yang berlaku. Sedangkan kompetensi adalah agen pembelajaran pada jenjang pendidikan. Kemudian untuk seseorang yang tidak memiliki ijazah atau sertifikat tetapi memiliki keahlian khusus yang diakui dan diperlukan sekolah, dapat diangkat menjadi pendidik ataupun tenaga kependidikan setelah melewati uji kelayakan dan kesetaraan. $^{12}$

1. Mutu tenaga pendidik dan tenaga kependidikan berdasarkan instrument pemetaan mutu di SMP Negeri 1 Keling Jepara

Pada pelaksanaan pemetaan mutu sekolah mengacu pada Standar Nasional Pendidikan (SNP). Ada 8 standar yang harus dipenuhi oleh sekolah. Untuk mengetahui sekolah sudah memenuhi standar atau belum, sekolah dianjurkan mengisi instrumen SNP yang ada di aplikasi eEDS yang nantinya akan menghasilkan peta mutu (capaian standar).

Kualifikasi pendidik dan tenaga kependidikan harus sesuai dengan PP No 19 tahun 2005 Bab VI yang dibuktikan dengan ijazah dan sertifikat keahlian yang relevan. Kepala sekolah SMP Negeri 1 Keling Jepara menghimbau masing-masing tenaga pendidik dan tenaga kependidikan untuk mengikuti peraturan yang sudah ditentukan, seperti yang sudah dijelaskan pada PP No 19 tahun 2005 pasal 29 ayat 3 bahwa tenaga pendidik pada SMP harus berkualifikasi minimal D IV atau Sarjana (S1) dengan latar belakang pendidikan yang sesuai dengan mata pelajaran yang diajarkan serta mempunyai sertifikat mengajar.

Berdasarkan data diketahui bahwa tenaga pendidik dan tenaga kependidikan di SMPN1 Keling Jepara berjumlah 43 orang berstatus PNS yang terdiri dari 34 guru termasuk kepala sekolah dan 9 tenaga pegawai. Ada satu guru yang pendidikan terakhir DIII. Berhubung sudah hampir pensiun, kepala sekolah harus merekrut guru baru agar tidak ada guru yang terbebani dengan adanya tambahan jam mengajar yang semula diampu oleh guru yang pensiun.

12 Hidayati, "Manajemen Pendidikan, Tenaga Kependidikan Dan Mutu Pendidikan" (IAIN IB Padang, n.d.). 
Dari hasil observasi peneliti di SMPN 1 Keling Jepara, menunjukkan bahwa rapor mutu pada standar pendidik dan tenaga kependidikan menunjukkan kemajuan dari tahun sebelumnya. Ini dapat dilihat dalam table berikut.

Tabel 1.

Rapor Mutu SMP Negeri 1 Keling Jepara

\begin{tabular}{|l|l|l|}
\hline Standar Nasional Pendidikan & \multicolumn{2}{|l|}{ Capaian standar } \\
\cline { 2 - 3 } & 2018 & 2019 \\
\hline Standar kompetensi lulusan & 5,96 & 6,99 \\
\hline Standar isi & 5,73 & 6,99 \\
\hline Standar proses & 6,45 & 6,99 \\
\hline Standar penilaian pendidikan denaga & 6,09 & 6,99 \\
\hline $\begin{array}{l}\text { Standar pendidik dan } \\
\text { kependidikan }\end{array}$ & $\mathbf{4 , 9 7}$ \\
\hline Standar sarpras & 3,13 & 5,6 \\
\hline Standar pengelolaan & 6,11 & 6,92 \\
\hline Standar pembiayaan & 6,14 & 6,99 \\
\hline
\end{tabular}

Hal ini juga diperjelas lagi oleh kepala sekolah yang mengatakan:

Berdasarkan hasil rapor mutu SMP N 1 Keling Jepara pada standar pendidik dan tenaga kependidikan menunjukkan peningkatan menuju level 4, itu artinya standar pendidik dan tenaga kependidikan mencapai standar maksimal 99\%.

Untuk mengetahui hasil seperti di atas, sekolah terlebih dahulu harus melaksanakan pemetaan mutu. Kegiatan dalam pemetaan mutu pendidikan dimulai dengan pengisian kuesioner di aplikasi e-EDS, pengumpulan data, pengembangan instrumen, analisis data, penentuan akar masalah dan penyusunan rekomendasi. Akses pengisian pemetaan mutu menggunakan aplikasi e-EDS, sekolah juga dapat mengunduhnya di laman: http://pmp.dikdasmen.kemdikbud.go.id. Secara teknis aplikasi EDS ini bersifat komponen operasional (add ons/pengayaan) dari aplikasi dapodik. Maka dari itu aplikasi EDS dapat di install dan berjalan jika di komputer sekolah sudah menginstall aplikasi dapodik. Setelah aplikasi terinstall maka secara otomatis aplikasi EDS akan mengambil identitas 
data pokok dari aplikasi dapodik. ${ }^{13}$ Tenaga pendidik dan tenaga kependidikan SMP N 1 Keling Jepara kompak mengisi kuesioner di aplikasi EDS versi 2019.09.01 yang didampingi oleh pengawas dan kepala sekolah.

Guru-guru SMP N 1 Keling Jepara bekerja sama melaksanakan pemetaan mutu untuk meningkatkan kualitas sekolah. Beberapa kuesioner yang harus di isi oleh responden ada lima hal yaitu: hasil belajar, isi pendidikan, proses pembelajaran, penilaian pembelajaran dan pengelolaan pendidikan. Lima kuesioner tersebut harus di isi sesuai dengan kondisi di sekolah, hal ini bertujuan agar pihak sekolah dapat memperoleh gambaran perkembangan kualitas sekolah dari tahun ketahun serta hasil pemetaan mutu bisa untuk menyusun program perbaikan guna mencapai pemenuhan SNP, baik pada tingkat satuan pendidikan, kabupaten sampai provinsi.

Yeni Tristiana S.Pd selaku guru bahasa Inggris sekaligus waka kurikulum, menjelaskan bahwa: Dilihat dari grafik radar PMP tahun 2019 pada SMP N 1 Keling Jepara ini menunjukkan bahwa pada standar pendidik dan tenaga kependidikan dan standar sarana prasarana terlihat adanya persilangan garis sedangkan standar yang lain tidak terjadi perpotongan. Hal inilah yang menunjukkan adanya penurunan nilai mutu pada kedua standar.

Untuk dapat mengetahui hal-hal yang mengakibatkan tidak terpenuhinya standar, perlu adanya analisis indikator dan sub indikator dari setiap standar. hal ini bertujuan untuk mengetahui masalah sekolah yang menghambat pencapaian pada masing-masing standar. dengan begitu sekolah perlu meninjau kembali capaian dari setiap indikator dan sub indikator.

Setelah sekolah melihat gambaran umum capaian SNP pada tahun 2019, hal yang perlu dilakukan sekolah selanjutnya adalah menganalisis masing-masing standar untuk mencari solusi pemecahan masalah dan memunculkan rekomendasi yang dijadikan program perencanaan pemenuhan mutu pada tahun berikutnya.

Instrumen pemetaan pada standar pendidik dan tenaga kependidikan memiliki 5 indikator yaitu: 5.1 (ketersediaan dan kompetensi guru sesuai ketentuan), 5.2 (ketersediaan dan kompetensi

${ }^{13}$ Kemendikbud, Petunjuk Aplikasi Evaluasi Diri Sekolah (EDS) Daring (Jakarrta: Kemendikbud, 2019). 
kepala sekolah sesuai ketentuan), 5.3. (ketersediaan dan kompetensi tenaga administrasi), 5.4. (ketersediaan dan kompetensi laboran) dan 5.5 (ketersediaan dan kompetensi pustakawan). Berdasarkan capaian hasil yang ada pada tenaga kependidikan seperti tenaga administrasi, laboran dan tenaga pustakawan mempunyai nilai paling rendah. Walaupun tenaga kependidikan di SMP N 1 Keling ada. Aspek kompetensi masih belum ada nilainya. Hal itu bisa terjadi jika responden tidak memasukkan data. Nilai data kompetensi guru dan kepala sekolah dapat diperoleh dari nilai Uji Kompetensi Guru (UKG) dan Uji Kompetensi Kepala Sekolah (UKKS).

Ketersediaan guru di SMP N 1 Keling Jepara mendapat nilai 6,58 sehingga masuk kategori menuju SNP 4. Sub indikator 5.1.1. tentang kualifikasi guru mendapat nilai 6,84, masuk kategori menuju SNP 4 . Berdasarkan data dokumentasi yang peneliti peroleh ada 30 guru berijazah S1, 3 guru berijazah S2 dan 1 guru berijazah DIII. Hal ini menunjukkan standar belum terpenuhi. Selanjutnya ada sub indikator 5.1.3. tentang tersedianya guru untuk tiap mata pelajaran mendapat nilai 7 atau bisa dikatakan mencapai SNP. Nilai capaian standar mendapat nilai sempurna seperti pada sub indikator 5.1.3. menunjukkan bahwa guru SMP N 1 Keling sudah mempunyai guru setiap mata pelajarannya. Berdasarkan observasi peneliti pada jadwal mata pelajaran SMP N 1 Keling Jepara menunjukkan bahwa setiap guru sudah memiliki mata pelajaran yang diampu. Sub indikator 5.1.4. tentang sertifikat pendidik mendapat nilai 5,33 dan masuk kategori menuju SNP 4. Berdasarkan wawancara peneliti dengan ibu Yeni Tristiana S.Pd menyatakan bahwa guru di SMP N 1 Keling Jepara ini berjumlah 48 guru dengan 34 guru ASN dan 14 GTT (guru TidakTetap).

Masrifah menambahkan: Karna memang guru GTT yang ada di provinsi Jawa Tengah sekarang ini lebih banyak daripada guru ASN, ya, Mbak, sehingga sekolah tidak punya pilihan lain untuk menerima guru GTT dengan alasan tidak mau proses pembelajaran terkendala. Jika menunggu dari dinas prosesnya lama mbk enggk mesti yang ditargetkan sekarang ada, begitu.

Dari pernyataan tersebut kepala sekolah mengambil GTT agar dapat membantu kelancaran proses belajar siswa. Umumnya di sekolah lain juga menggunakan cara yang sama sebagai solusi bagi sekolah yang ingin membutuhkan guru dengan cepat. 
Selanjutnya untuk sub indikator 5.1.5. sampai 5.1.8. tentang kompetensi guru meliputi kompetensi pedagogik, kompetensi kepribadian, kompetensi profesional dan kompetensi sosial menunjukkan nilai 0 , hal ini dijelaskan dengan hasil wawancara peneliti dengan operator sekolah SMP N 1 Keling bapak Agus P., S.Pd, bahwa:

Untuk nilai rapor mutu tepatnya pada indikator kompetensi guru, kemaren saat mengisi instrumen EDS untuk bagian standar PTK mengalami gangguan, sehingga data tidak terbaca, yang memungkinkan nilainya kosong.

Dari penjelasan di atas, Agus menyatakan keluhannya saat mengetahui nilai standar PTK banyak yang tidak muncul. Banyak operator sekolah mengeluhkan hal yang sama mengenai nilai pada standar PTK.

Dari indikator 5.2 (Ketersediaan dan kompetensi kepala sekolah sesuai ketentuan) yang diperoleh kepala sekolah mendapat nilai sempurna yaitu 7 yang di ikuti dengan sub indikator dari 5.2.1. sampai 5.2.6. hal ini menunjukkan bahwa kepala sekolah SMP N 1 Keling telah memenuhi kualifikasi yang sudah ditentukan.

Berdasarkan hasil wawancara peneliti dengan ibu Masrifah selaku kepala sekolah SMP N 1 Keling menjelaskan bahwa : Saya sebagai kepala sekolah sudah mempunyai ijazah $\mathrm{S} 1$, pangkat yang saya miliki pembina IV/a, waktu diangkat pada umur 56 tahun dengan mempunyai pengalaman mengajar 5 tahun serta sertifikat kepala sekolah yang diperoleh dari LP2KS.

Berdasarkan hasil wawancara di atas menunjukkan bahwa kepala sekolah SMP N 1 Keling Jepara sudah memenuhi kualifikasi umum yang sudah tertulis dalam permendiknas No. 13 tahun 2007 tentang standar kepala sekolah, hal ini menunjukkan bahwa kepala sekolah SMP N 1 Keling Jepara memiliki komitmen untuk meningkatkan kualitas sekolah. Sedangkan untuk kompetensinya juga sama dengan nilai kompetensi guru, tidak ada nilai yang muncul.

Tenaga administrasi SMP N 1 Keling mendapat nilai 4,2, masuk kategori menuju SNP 3, hal ini menunjukkan bahwa pelayanan yang ada di SMP N 1 Keling kurang maksimal. Tenaga administrasi hanya mendapat dua nilai yaitu ada di indikator 5.3 (ketersediaan dan kompetensi tenaga administrasi sesuai ketentuan)dan sub indikator 5.3.4. yang memperoleh nilai 7 . 
Menurut hasil wawancara dengan bapak Sutejo S.Pd selaku kepala tenaga administrasi menyatakan bahwa:Semua staf yang ada di kantor, alhamdulillah sudah memenuhi kualifikasi yang sudah ditentukan, dan semua staf sudah mahir menggunakan komputer. Termasuk saya sebagai ketua TU sudah memenuhi kualifikasi seperti minimal D3, memiliki pengalaman kerja selama 4 tahun dan memiliki sertifikat kepala tenaga administrasi sekolah dari lembaga yang ditetapkan oleh pemerintah.

Berdasarkan struktur organisasi SMPN 1 Keling yang peneliti dapatkan dari RKS menunjukkan bahwa ada kepala tenaga administrasi serta tenaga pelaksana urusan administrasi seperti kepegawaian, sarpras, keuangan, humas, kurikulum, kesiswaan, operator dan tenaga pelayanan khusus yang terdiri dari penjaga sekolah, petugas kebersihan dan satpam. Kemungkinan data tidak bisa terdeteksi karena adanya kesalahan dalam aplikasi atau belum sinkronnya dapodik dengan baik.

Pada indikator 5.4 (ketersediaan dan kompetensi laboran sesuai ketentuan) ketersediaan tenaga laboran mempunyai sub indikator yang sama dengan tenaga administrasi yaitu harus memiliki kepala tenaga. Hampir semua indikator dan sub indikator tidak memiliki nilai alias 0 . Berdasarkan hasil observasi peneliti SMP N 1 Keling mempunyai satu kepala laboratorium dan laboran yang dibuktikan dengan struktur organisasi SMP N 1 Keling yang ada pada RKS tahun ajaran 2020/2021.

Sub indikator 5.4.5. tentang tersedianya tenaga teknis laboran, hampir semua sekolah tidak memilikinya. Karena sekolah mempunya guru IPA yang rata-rata sekolah menjadikannya sebagai guru IPA sekaligus laboran/teknisi hal ini dilakukan karena sekolah kekurangan tenaga yang ahli dalam pengelolaan laboratorium.

Pada indikator 5.5 (ketersediaan dan kompetensi pustakawan sesuai ketentuan) menjadi indikator terakhir dari standar pendidik dan tenaga kependidikan. Namun pada indikator 5.5 mendapatkan hasil yang sama dengan indikator 5.4, yaitu sama-sama tidak ada nilai. Jika sistem memberikan nilai 0 itu artinya sekolah tidak mempunyai kepala pustakawan maupun tenaga pustakawan. Berdasarkan observasi peneliti di SMP N 1 Keling, sekolah mempunyai 1 kepala perpustakaan dan 1 petugas perpustakaan serta dibantu suka relawan guru yang terkumpul dalam pengurus harian yang didapat peneliti dari RKS tahun ajaran 2020/2021. 
Pada umumnya nilai tenaga kependidikan berasal dari data dapodik, jika di rapor mutu nilai tenaga kependidikan belum ada maka ada kemungkinan data dapodik belum tersinkronkan dengan baik. Jadi, dalam melaksanakan pemetaan mutu di SMP N 1 Keling menggunakan aplikasi khusus yang sudah disiapkan oleh Kemendikbud yaitu e-EDS yang berisi instrumen berdasarkan delapan SNP yang harus diisi oleh komponen sekolah. dari pelaksanaan pemetaan mutu ini dijadikan sekolah sebagai evaluasi untuk mengetahui kondisi dan situasi yang dapat memberikan gambaran capaian mutu berdasarkan standar pendidik dan tenaga kependidikan. Namun saat pelaksanaan pemetaan mutu tahun kemaren ada kendala di aplikasi EDS yang tidak bisa secara maksimal membaca seluruh data yang ada pada aplikasi dapodik

SMP N 1 Keling Jepara sudah melangsungkan SPMI selama empat tahun dimulai dari tahun 2016-2019 dan 2020 pada bulan Desember yang dibantu oleh Tim Penjaminan Mutu Pendidikan Sekolah (TPMPS) yang terdiri dari perwakilan pimpinan satuan pendidikan, pendidik dan tenaga kependidikan serta komite pendidikan. Tim ini bertugas mengkoordinasikan pelaksanaan SPMI, melaksanakan pemetaan mutu, membina, mendampingi dan mengawasi komponen pendidikan, monitoring, evaluasi program dan membuat rekomendasi kepada kepala sekolah.

Bagi SMP N 1 Keling Jepara, hasil pemetaan mutu dijadikan sebagai acuan perencanaan pelatihan pendidik dan tenaga kependidikan, misalnya rapor PMP pada standar pendidik dan tenaga kependidikan dalam sub indikator 5.1.5 kompetensi pedagogik minimal baik, menunjukkan hasilnya masuk dalam level I (menuju SNP 1) maka SMP N 1 Keling Jepara melalui RKS perlu memprogramkan pelatihan bagi guru khususnya pada materi kompetensi pedagogik dan begitu seterusnya. SMP N 1 Keling Jepara berusaha berkomitmen meningkatkan mutu sekolahnya dengan mengikuti kebijakan yang diberikan pemerintah.

Berdasarkan deskripsi data peneliti menunjukkan bahwa data mutu tenaga pendidik dan tenaga kependidikan SMPN 1 Keling telah mengalami kenaikan nilai dari tahun sebelumnya. Hal ini dibuktikan dengan hasil rapor mutu sekolah yang di peroleh sekolah dari mengisi instrumen pemetaan mutu. Walaupun tidak sepenuhnya memenuhi namun nilai yang didapat membuktikan adanya komitmen dari semua pihak sekolah. 
Seperti pernyataan dari Direktorat jendral pendidikan dasar dan menengah hasil dari pemetaan mutu yaitu rapor mutu memberikan gambaran serta manfaat sebagai acuan dalam perencanaan perbaikan dan peningkatan mutu. Kegiatan pemetaan mutu dilakukan melalui aplikasi EDS dengan mengacu pada delapan SNP. Pada pembahasan mutu tenaga pendidik dan tenaga kependidikan berdasarkan instrumen pemetaan mutu di SMP Negeri 1 Keling, peneliti menggunakan beberapa metode dalam pengumpulan datanya, yaitu wawancara, dokumentasi sekolah dan observasi.

Berdasarkan nilai dari instrumen standar PTK di atas, indikator yang mendapatkan nilai paling banyak adalah 5.2 standar kepala sekolah dengan memperoleh nilai 7 dalam kategori memenuhi SNP. Berikutnya ada di indikator 5.1 dari standar guru yaitu 6,58 mendapat kategori menuju SNP 4 dan yang terakhir indikator 5.4 standar tenaga administrasi 4,2 dalam kategori menuju SNP 3. Sayangnya untuk indikator 5.4 dan 5.5 tidak memperoleh nilai sehingga hasil rapor mutu standar PTK menunjukkan nilai 0. Berdasarkan penjelasan dari operator sekolah menyatakan bahwa ada gangguan aplikasi untuk standar PTK, berhubung data PTK disambungkan dengan kinerja aplikasi dapodik maka sekolah juga di haruskan mensinkronkan aplikasi dapodik.

Sebagaimana yang dikatakan oleh LPMP untuk mengisi aplikasi dapodik harus sesuai dengan kondisi sekolah serta rajin mensinkron aplikasi dapodik secara berkala. ${ }^{14}$ Penelitian ini mendukung penelitian dari Rahmad Sodiq tentang evaluasi penjaminan mutu pendidikan di SMK N 1 Magelang. Dengan hasil penelitian menunjukkan bahwa pemetaan mutu di sekolah mampu memberikan gambaran mutu secara akurat. $^{15}$

Berdasarkan hasil analisis diatas bisa diambil kesimpulan bahwa pelaksanaan pemetaan mutu di SMPN 1 Keling sudah terlaksana dengan baik dengan dibantu kerja sama dari masing-masing tenaga sekolah, sehingga sekolah mendapat gambaran sampaimana capaian pemenuhan standar disetiap tahunnya dan dapat mengevaluasi tiap indikator atau sub indikator yang belum memenuhi bisa dibuatkan solusi atau program peningkatan.

\footnotetext{
${ }^{14}$ I Gede Satri Wibawa, "Peta Mutu Pendidikan Jenjang SMP," n.d.

${ }^{15}$ Rahmad Sodiq, "Evaluasi Penjaminan Mutu Pendidikan Di SMK N 1 Magelang" (n.d.).
} 
2. Peningkatan mutu tenaga pendidik dan kependidikan berdasarkan standar pendidik dan tenaga kependidikan di SMPN 1 Keling

Beberapa upaya yang dilakukan kepala sekolah dalam meningkatkan mutu tenaga pendidik dan tenaga kependidikan di SMP N 1 Keling sebagaimana berikut:

\section{a. Pemberian izin belajar}

Upaya yang diberikan kepala sekolah dalam meningkatkan kualifikasi pada tiap tenaga sekolah adalah dengan memberikan kesempatan dan dukungan bagi tenaga pendidik untuk melanjutkan studinya.

Hal ini dinyatakan kepala sekolah:...saya sangat mengapresiasi guru yang mau melanjutkan studinya lagi, kebetulan ada tiga guru yang sudah memiliki ijazah S2 selebihnya S1 dan program ini sudah terlaksana lama sebelum saya menjabat sebagai kepala sekolah di SMP Negeri 1 Keling.

Dari hasil wawancara diatas menjelaskan bahwa kepala sekolah SMP Negeri 1 Keling selalu mengizinkan guru untuk melanjutkan studinya. Pada intinya kepala sekolah akan selalu mengizinkan kegiatan yang mengarah pada peningkatan pembinaan sumber daya sekolah.

\section{b. In Hous Training (IHT)}

Pelatihan In Hous Training (IHT) merupakan program pelatihan yang diadakan sekolah sendiri, sebagai upaya untuk meningkatkan kompetensi guru dalam menjalankan pekerjaannya dengan mengoptimalkan potensi yang ada.

Hal yang melatar belakangi adanya program IHT di SMP $\mathrm{N} 1$ Keling adalah ketika sekolah tidak lagi melangsungkan proses belajar mengajar lewat tatap muka namun lewat daring (online). Dengan adanya imbauan dari pemerintah untuk menggunakan daring saat pembelajaran, guru mendapat kesempatan untuk memanfaatkan teknologi yang ada.

Untuk dapat melangsungkan KBM lewat daring, alangkah baiknya jika guru terlebih dahulu mengetahui cara mengoperasikan aplikasi belajar. Maka Ibu Masrifah selaku kepala sekolah menyatakan : Upaya yang tepat untuk mengatasi permasalah ini yaitu mengadakan pelatihan IHT, Mbak. Karena pelaksanaan bisa diatur sendiri oleh sekolah, 
menghemat waktu, biaya dan dapat memakai kemampuan guru yang ada di sekolah.

Dengan adanya pelatihan IHT ini menjadi sarana kepala sekolah untuk menghadapi keadaan yang serba online seperti pada tahun 2020. Pelatihan IHT ini juga mampu meningkatkan kompetensi guru dengan mendatangkan guru yang berkompeten.

Pelaksanaan IHT yang dilaksanakan di SMP N 1 Keling diikuti oleh 48 guru dan 10 tenaga kependidikan dengan mengikuti protokol kesehatan. Selama pelaksanaan para guru memperhatikan dengan seksama cara penggunaan aplikasi belajar, hal ini bertujuan agar para guru dapat menyelenggarakan proses pembelajaran lewat daring secara maksimal.

\section{c. Musyawarah Guru Mata Pelajaran (MGMP)}

MGMP merupakan forum atau wadah kegiatan profesional guru dengan mata pelajaran sejenis. Dengan adanya forum ini diharapkan para guru mampu meningkatkan profesionalisme dan kualitas diri dalam mengajar dan mendidik siswa siswinya. ${ }^{16}$

"MGMP ini adalah kumpulan atau organisasi untuk guru dengan mata pelajaran yang sama, MGMP dibuat untuk berdiskusi membantu mencari solusi untuk guru yang masih kesulitan saat melangsungkan pembelajaran di kelas."

Dengan adanya MGMP di SMPN 1 Keling, guru dapat bertukar pikiran serta berbagi pengalaman dengan teman sejawat, sehingga dapat meringankan beban guru. Program MGMP di SMPN 1 Keling diadakan seminggu satu kali atau bisa lebih tergantung pimpinan forum. Seperti pernyataan dari ibu Yeni guru bahasa Inggris SMPN 1 Keling sekaligus pimpinan MGMP Kabupaten, bahwa:

Pelaksanaan MGMP ini dilaksanakan seminggu sekali di bulan ini atau bisa lebih tergantung pimpinan dari masing-masing grup mapel.

Selain itu ibu Yeni juga menceritakan pengalamannya saat ikut serta dalam forum MGMP. Yaitu sebagai berikut : Sebelum saya ditunjuk sebagai pemimpin forum, hal pertama yang saya dapat saat ikut MGMP ini adalah dapat membantu saya dalam menyusun dan mengembangkan

${ }^{16}$ Irman Natsir Andriani, Wiwik, "Peran MGMP Terhadap Kompetensi Guru MTK Di Tingkat SMA," Jurnal Koulutos 2, no. 1 (2019). 
RPP serta mengatasi siswa siswi di kelas agar semakin bersemangat dalam mengikuti pembelajaran bahasa inggris.

Dari pernyataan tersebut dapat disimpulkan bahwa MGMP sudah efektif dalam mengembangkan profesionalisme guru, sebagai upaya menjamin mutu pendidikan. Walaupun begitu, di dalam sebuah forum tentu harus ada seseorang yang bisa memberikan dorongan maupun motivasi untuk menyadarkan anggota yang lain untuk ikut meningkatkan kualitas diri.

Pelaksanaan MGMP terlaksana dengan baik dengan pemateri yang berkompeten. Selain itu para peserta menikmati materi diskusi yang diberikan, karena sangat bermanfaat untuk guru dalam memberikan pembelajaran yang efektif untuk peserta didik di kelas.

\section{d. Pendidikan dan pelatihan (diklat)}

Kepala sekolah SMPN 1 Keling juga berupaya untuk meningkatkan kompetensi dan profesionalitas tenaga pendidik. Kepala sekolah sudah menyiapkan perencanaan untuk mengirimkan para tenaga pendidik agar ikut serta dalam seminar, diklat dan workshop yang diselenggarakan di luar sekolah. Pelatihan ini diberikan untuk membantu guru dalam meningkatkan kemampuan serta siap dengan perubahan apapun, seperti perubahan yang sempat terjadi kemaren yaitu perubahan KTSP ke kurikulum 13.

Mengingat tugas guru begitu berat maka sangat penting pelatihan untuk guru. Dengan tujuan agar selalu ter-update pengetahuan, wawasan, dan keterampilannya dalam mengembangkan profesi. Selain pelatihan untuk tenaga pendidik ada juga pelatihan untuk tenaga kependidikan namun pelatihan yang terkhususkan untuk tenaga kependidikan tidak sebanyak pelatihan yang disediakan untuk guru.

Upaya kepala sekolah dalam meningkatkan mutu tenaga pendidik dan tenaga kependidikan SMPN 1 Keling menunjukkan bahwa kepala sekolah memahami kebutuhan yang dibutuhkan oleh tenaga pendidik dan tenaga kependidikan. Seperti pelaksanaan MGMP untuk guru bahasa Inggris. upaya ini untuk meningkatan mutu melalui kegiatan MGMP seperti peningkatan hasil belajar siswa, pelaksanaan penilaian, pengembangan sikap profesional, penerapan inovasi dan perkembangan baru dalam dunia pendidikan. Selain itu ada juga diklat yang menjadi 
andalan kepala sekolah untuk meningkatkan wawasan serta kemampuan guru yang dimilikinya.

Pelatihan untuk tenaga kependidikan tidak sebanyak yang dimiliki guru karena tugas tenaga kependidikan yang tidak setiap hari berinteraksi dengan siswa. Walaupun begitu tenaga kependidikan tetap membutuhkan pelatihan untuk meningkatkan kemampuannya dalam melayani administrasi sekolah. untuk itu pelatihan IHT dapat menjadi solusi kepala sekolah untuk memberikan pengetahuan serta tanggung jawab atas pekerjaannya.

\section{KESIMPULAN}

Berdasarkan analisis terhadap data-data yang diperoleh, maka dapat ditarik kesimpulan sebagai berikut:

1. Data pemetaan mutu tenaga pendidik dan tenaga kependidikan berdasarkan standar mendapat kenaikan dari nilai sebelumnya. Hal ini ditunjukkan dari masing-masing nilai indikator standar pendidik dan tenaga kependidikan, sebagai berikut :

a. Pada standar pendidik indkator 5.1 mendapat nilai 6,58 dalamkategori 4 . Ada 8 sub indikator yang perlu dianalisis sekolah, yang pertama sub indikator 5.1.1. 6,84 mendapatkan kategori 4 karna masih ada guru yang belum memenuhi kualifikasi, sub indikator 5.1.3. mencapai SNP dengan dibuktikan dengan jadwal mengajar guru tiap kelas, sudah memenuhi semua mata pelajaran. Selanjutnya sub indikator 5.1.4. 5,33 mendapat kategori SNP 4 disebabkan adanya guru GTT yang belum memiliki sertifikat pendidik. Untuk sub indikator 5.1.5. sampai 5.1.8. tidak mendapatkan nilai karna ada masalah pada aplikasi EDS dengan aplikasi dapodik.

b. Standar kepala sekolah 5.2. pada kualifikasi mendapat nilai 7 atau mencapai SNP. Hal ini dibuktikan dengan pernyataan ibu Masrifah S.Pd selaku kepala sekolah dan dokumen yang ada pada tenaga administrasi.

c. Standar tenaga administrasi 5.3 mendapat 4,2 kategori SNP 3. Pada standar administrasi hanya memperoleh dua nilai, karna adanya masalah dalam aplikasi.

d. Standar laboran 5.4. dan standar pustakawan 5.5. tidak mendapatkan nilai, namun berdasarkan observasi peneliti tersedianya kepala 
laboratorium, laboran, kepala perpustakaan dan tenaga perpustakaan tercantum dalam struktur organisasi SMP Negeri 1 Keling Jepara tahun pembelajaran 2020/2021.

2. Upaya yang diberikan kepala sekolah untuk meningkatkan mutu pendidik dan tenaga kependidikan sudah terlaksana dengan baik. Hal ini dibuktikan dengan data foto dokumentasi sekolah serta pernyataan para guru yang ikut serta dalam pelatihan, seperti pelaksanaan MGMP bahasa Inggris di ikuti oleh ibu Yeni Tristiana S.Pd menyatakan bahwa pelaksanaan MGMP ini membantu guru dalam proses pembelajaran serta pelatihan IHT yang menjadi sarana dalam meningkatkan kemampuan guru dalam memahami pemakaian aplikasi belajar. Pelatihan IHT juga membantu tenaga kependidikan dalam meningkatkan kemampuan IT.

\section{DAFTAR PUSTAKA}

2016, Peraturan menteri pendidikan dan kebudayaan No. 28 tahun.

Sistem penjaminan mutu pendidikan dasar dan menengah (2016).

Andriani, Wiwik, Irman Natsir. "Peran MGMP Terhadap Kompetensi

Guru MTK Di Tingkat SMA." Jurnal Koulutos 2, no. 1 (2019).

Corinorita. "Pelaksanaan in Hous Training Untuk Meningkatkan

Kompetensi Guru Dalam Menyususn RPP Di SMP." Jurnal Ilmu

Pendidikan Sosial, Sains, Dan Humaniora 3, no. 1 (2017).

Damanik, Jafriansen. "Upaya Dan Strategi Pemenuhan SNP." JDP 8, no. 3 (2015).

Fitrah, Muh. "Peran Kepala Sekolah Dalam Meningkatkan Mutu

Pendidikan." Jurnal Penjaminan Mutu 7, no. 28 (2017).

Hidayati. "Manajemen Pendidikan, Tenaga Kependidikan Dan Mutu

Pendidikan." IAIN IB Padang, n.d.

Kemendikbud. Petunjuk Aplikasi Evaluasi Diri Sekolah (EDS) Daring. Jakarrta: Kemendikbud, 2019.

LPMP. Mekanisme Pemetaan Mutu Tahun 2019. Banten: Direktorat

jendral pendidikan dasar dan menengah kementerian pendidikan dan kebudayaan, 2019.

Muhammad, Hamid. Petunjuk Pelaksanaan: Penjaminan Mutu

Pendidikan Oleh Satuan Pendidikan. Jakarrta: Kemendikbud, 2016. Muhandri, Tjahja, Darwin Kadarisma. Sistem Jaminan Mutu Industri

Pangan. Bogor: IPB Press, 2012.

Prayoga, Ari. "Manajemen Penjaminan Mutu Madrasah." UIN Sunan

Gunung Djati Bandung, n.d.

Ridwan A. Sani, Rusjdy S. Arifin, MuhammadRif' an, Cepi Triatna. Sistem 
Penjaminan Mutu Internal (SPMI). 1st ed. Tangerang: Tira Smart, 2018.

Sallis, Edward. Total Quality Management in Education. Edited by Ahmad Ali Riyadi dan Fahrurrozi. Yogyakarta: IRCisoD, 2012.

Sodiq, Rahmad. "Evaluasi Penjaminan Mutu Pendidikan Di SMK N 1

Magelang," n.d.

Sujak, Abi. Panduan Pelaksanaan Pemetaan Mutu Pendidikan. Jakarta:

Kementerian Penddik dan Kebudayaan Badan Pengembangan

Sumber Daya Manusia Pendidikan dan Kebudayaan dan Penjaminan Mutu Pendidikan, 2013.

Surnaya, Ketut, Wayan Murnasa. Peta Mutu Pendidikan Jenjang SD

Kabupaten Bangli. Bali: LPMP Bali, 2018.

Wibawa, I Gede Satri. "Peta Mutu Pendidikan Jenjang SMP," n.d. 